\title{
Nicotinic stimulation in two populations: aircraft pilots and dementia patients Jerome Yesavage
}

\author{
Address: Aging Clinical Research Center, Stanford University School of Medicine, CA, USA \\ from International Society on Brain and Behaviour: 3rd International Congress on Brain and Behaviour \\ Thessaloniki, Greece. 28 November - 2 December 2007 \\ Published: 17 April 2008 \\ Annals of General Psychiatry 2008, 7(Suppl I):S76 doi:10.1 186/I744-859X-7-SI-S76
}

This abstract is available from: http://www.annals-general-psychiatry.com/content/7/SI/S76

(c) 2008 Yesavage; licensee BioMed Central Ltd.

Our previous studies in a professional flight simulator have demonstrated a positive effect of nicotine on a complex cognitive task, flying an aircraft. This effect may be mediated by working memory or attentional processes, in addition to direct effects on sort-term and long-term memory. Similar data exist for galantamine's nicotinic effects in vivo and in vitro. In a similar manner to the effects of nicotine on aircraft pilots, galantamine's effects might lead to specific improvements attention, which is suggested by its having positive effects on severely affected Alzheimer's patients who memory function is virtually absent. Data also exist suggestion a neuroprotective effect of galantamine, however studies suggesting this effect have been limited to one year duration. Future studies of such compounds should focus on their effects on attention and neuroprotection longitudinally across all levels of Alzheimer's pathology. 